\title{
Solar exposure(s) and facial clinical signs of aging in Chinese women: impacts upon age perception
}

This article was published in the following Dove Press journal:

Clinical, Cosmetic and Investigational Dermatology

10 February 2015

Number of times this article has been viewed

\section{Frederic Flament ${ }^{1}$ \\ Roland Bazin² \\ Huixia Qiu ${ }^{3}$ \\ Chengda $\mathrm{Ye}^{3}$ \\ Sabine Laquieze 4 \\ Virginie Rubert ${ }^{\prime}$ \\ Aurelie Decroux' \\ Elisa Simonpietri ${ }^{5}$ \\ Bertrand Piot ${ }^{1}$}

'L'Oreal Research and Innovation, Paris, France; ${ }^{2}$ RB Consult, Bievres, France; ' ${ }^{2}$ 'Oreal Research and Innovation, Shanghai, People's Republic of China; ${ }^{4}$ Private Dermatology

Consultancy, Montpellier, France;

${ }^{5}$ Biotherm International, Levallois-

Perret, France
Correspondence: Frederic Flament Department of Applied Research and Development, L'Oreal Research and Innovation, 188, Rue Paul Hochart, 94550 Chevilly-Larue, Paris, France Email fflament@rd.loreal.com

\begin{abstract}
A new reference clinical atlas of facial signs dedicated to photoaging was applied to 301 Chinese women of various ages through standardized photographs. Such approach aimed at better describing the facial changes induced by both real/chronological age and sun exposure and their respective impact on two subcohorts of different behavior with regard to sun exposure. A total of 28 various facial signs were individually graded according to their severity by a panel of experts, and a perceived apparent age of each subject was assessed. Results showed that the severity of major signs significantly increased rather linearly with age, with a higher rate in sun-exposed subjects as compared with subjects who regularly avoid sun exposure. The severity of facial signs, all impacted by sun exposure, better correlated with perceived apparent age than real/chronological age. The protocol used in the present work, similar to that previously applied to two cohorts of French women, assigned a greater impact of sun exposure in the facial aging signs of Asian women - all clinical signs are influenced by extrinsic factors - as compared with Caucasian women of comparable ages, likely related to much more intense ultraviolet (UV) radiation.
\end{abstract}

Keywords: photoaging, clinical evaluation, UV, perceived apparent age, solar exposure

\section{Introduction}

"Nature makes humans the same. Life makes them different" (Confucius). Combined with those induced by chronological aging, sun-induced damages upon the human skin are the subjects of an abundant literature. The latter is somewhat restricted to Caucasian populations ${ }^{1}$ due to their higher skin sensitivity to solar rays, ie, subjects with fair skins (phototypes I and II) are more prone to serious health consequences in the long-term, including melanoma. With regard to Asian populations, a few works have described the impact of sun exposure upon facial skin. ${ }^{2-4}$ Chung et al. ${ }^{5}$ proposed two specific scales to characterize photoaging in Korean people, whereas another study in Japanese subjects illustrated the influence of sun exposure and lifestyle upon photoaging. ${ }^{6}$ An interesting paper $^{7}$ compared Asian and Caucasian photoinduced damages on the skin of French (living in Besançon) and Chinese women (living in Suzhou) living under rather similar climatic conditions (in terms of sunshine and rainfall). However, such clinical assessments, although carried out by the same dermatologist, do not allow the relative contribution of photoaging to the overall aging process, ie, the combined effects of chronological (intrinsic) and sun-induced (extrinsic) damages, among these two ethnic groups to be estimated. A recent study, focusing on a Caucasian population living in a sunny region of France, ${ }^{8}$ proposed accurate criteria of clinical evaluation and suggested that approximately $80 \%$ of all facial aging signs in this population 
are linked to sun exposure. The proportion of facial aging due to sun exposure is still ignored with regard to an Asian population, the constitutive pigmentation of which (phototypes III and IV mostly) may suggest a less sensitive skin than that of Caucasians, albeit exposed to higher ultraviolet (UV) radiation. In addition, Asian cultures have understood, for centuries, the deleterious impact of sun exposure upon skin. This awareness explains the daily behavior of many Asian people on sunny days where umbrellas, UV masks, and photoprotective cosmetic products are commonly used. In brief, whereas Caucasians may be sun-seeking, many Asian people hide from the sun, suggesting that the contribution of sun exposure to signs of facial aging in Asians should be lower than that in Caucasians, despite higher UV radiation. Accordingly, the present work attempted to address a two-fold objective. On one hand, our work aimed at evaluating through a protocol, similar to the one used in a sunny southern region of France (Montpellier, latitude $43.5^{\circ} \mathrm{N}$ ), ${ }^{8}$ the contributing part of solar exposure in the overall aging process of facial traits through the clinical assessments of 28 facial signs in 301 Chinese women of various ages. On the other hand, our study aimed at describing the possible impacts of these clinical signs upon perceived apparent age, that is, a younger or older appearance than real/chronological age.

\section{Materials and methods Location of the study and description of the subjects}

The study was conducted in Guangzhou (Canton, $22^{\circ} \mathrm{N}$, $\left.113^{\circ} \mathrm{E}\right)$, the capital of the Guangdong region, where a high solar irradiation level (10 hours/day) is commonly found (average annual Ultraviolet A (UV A) doses are 1,050 $\mathrm{kJ} \cdot \mathrm{m}^{-2} \cdot$ day $^{-1}$ and average annual Ultraviolet B (UV B) doses are $28 \mathrm{~kJ} \cdot \mathrm{m}^{-2} \cdot$ day $\left.^{-1}\right){ }^{9,10}$ In addition to UV radiation (280$400 \mathrm{~nm})-7 \%$ of the solar energy received by human skin - previous literature has specified the visible light spectrum (400-760 $\mathrm{nm}$ ) and the infrared (IR) radiation (760-3,000 $\mathrm{nm}$ ) proportions of solar energy affecting skin, that is, 39\% and 54\%, respectively. Infrared A (IRA) radiation (760-1,440 $\mathrm{nm}$ ), which represents $30 \%$ of IR radiation, should be noted because of its deep penetration into the skin, especially the dermis, as well as its impact on higher phototypes. ${ }^{11,12}$

In total, 301 healthy Chinese women aged 20-80 years were recruited through a clinical assessment carried out by a dermatologist to ensure absence of any particular skin disorder other than dry or greasy skin. Subjects had lived for more than 10 years in the city of Guangzhou and, for most of them, both their mother and father were Guangzhouese.
Recruitment from this location where subjects had lived in the same environment and climate for a long time avoided biases due, for example, to lifestyle and pollution and ensured the focus was mainly on the impact of solar exposure. Smoking habits were not investigated during the selection of volunteers due to the fact that it has been previously observed in the literature that skin damages (telangiectasia and elastosis) due to sun exposure is far more important than that induced by cigarette smoking. ${ }^{13}$

All subjects completed a questionnaire that mainly focused on behavior with regard to sun exposure (time of exposure each day and each week during their lifetime, UV protection habits, types of transportation used, outdoor activities and leisure, outdoor vs indoor work). The latter allowed us to create two subcohorts of similar size, that is, sun-phobic (S-P) subjects (140 women) who try to systematically avoid sun exposure by all means (hats, umbrellas, masks, UV protecting cosmetic products, fewer outdoor activities, etc) and normal (sun) exposure (NE) subjects (161 women) who do not particularly pay attention to sun exposure in their daily activities. Both groups were balanced in age and phototypes (II to IV) and further subdivided into 10-year age classes (20-29, 30-39, etc) for statistical analysis. Distribution of panelists among age groups and the two subcohorts is presented in Table 1. Lifetime solar exposure is described in Table 2. A weekly duration of solar exposure for NE subjects three times higher than S-P subjects can be noticed throughout the life span.

All subjects were informed about the objective of the study and signed an informed consent form.

\section{Picture acquisition}

Volunteers were photographed under standard conditions afforded by the Bench HeadScan (Orion Concept) using a Nikon D300 digital camera fitted with a Nikon $105 \mathrm{~mm}$ lens (200 ISO sensitivity, 1/60 second exposure time, minimum aperture f/32). For each subject, a set of three photographs

Table I Distribution of volunteers among age classes and for the two subcohorts (sun-phobic and normal exposure)

\begin{tabular}{llll}
\hline Age (years) & Sun-phobic & Normal exposure & Total \\
\hline $20-29$ & 28 & 22 & 50 \\
$30-39$ & 28 & 22 & 50 \\
$40-49$ & 20 & 31 & 51 \\
$50-59$ & 20 & 31 & 51 \\
$60-69$ & 21 & 29 & 50 \\
$70-80$ & 23 & 26 & 49 \\
Total & 140 & 161 & 301 \\
\hline
\end{tabular}


Table 2 Description of the two subcohorts cohorts (sun-phobic and normal exposure) regarding the solar exposure behavior each day and week during volunteers' lifetimes - according to the questionnaire completed by each subject

\begin{tabular}{llllllllll}
\hline & $\begin{array}{l}\text { Period of lifetime } \\
\text { (age in years) }\end{array}$ & $\mathbf{0 - 1 0}$ & $\mathbf{1 0 - 2 0}$ & $\mathbf{2 0 - 3 0}$ & $\mathbf{3 0 - 4 0}$ & $\mathbf{4 0 - 5 0}$ & $\mathbf{5 0 - 6 0}$ & $\mathbf{6 0 - 8 0}$ & Average \\
\hline Hours per day & Sun-phobic & 3.55 & 3.59 & 2.99 & 2.84 & 2.78 & 3.31 & 3.40 & 3.21 \\
& Normal exposure & 4.04 & 4.57 & 5.02 & 5.07 & 5.11 & 4.63 & 4.31 & 4.68 \\
Days per week & Sun-phobic & 2.25 & 2.32 & 2.07 & 1.79 & 1.60 & 1.92 & 1.91 & 1.98 \\
& Normal exposure & 3.24 & 4.11 & 4.72 & 4.94 & 4.93 & 3.77 & 3.27 & 4.14 \\
Hours per week & Sun-phobic & 7.99 & 8.34 & 6.18 & 5.08 & 4.47 & 6.35 & 6.49 & 6.41 \\
& Normal exposure & 13.10 & 18.80 & 23.68 & 25.02 & 25.19 & 17.44 & 14.13 & 19.62 \\
\hline
\end{tabular}

was obtained: one front, full-face and two others from $45^{\circ}$ left and right sides from the nose axis.

During photographic shots, all subjects wore a white cotton cap to cover their head hair, to avoid its possible influence (volume and color) during the scoring phases of clinical signs and the assessment of a perceived apparent age from full-face photographs.

\section{New clinical standardized photographic scales}

An exhaustive Asian clinical reference divided into main clinical clusters (wrinkles and skin texture, ptosis and sagging, pigmentation disorders and others) was previously published based on Chinese (Shanghai) and Japanese (Tokyo) typology studies. ${ }^{14}$ Studies in the Guangdong region were opportunities to complete objective evaluation criteria with new clinical signs linked to sun exposure and less noticed in previously investigated Asian cities of northern latitudes. ${ }^{15}$

The study was designed as in the previous work ${ }^{8}$ on French women for designing new scales with a robust validation process. ${ }^{12}$ All pictures were observed by a panel of five experts who defined new signs/location and selected the most representative images of the considered clinical sign to obtain linear photographic scales of $0-5,0-6$, or $0-8$ scales ( 0 being minimal whereas 5,6 , or 8 indicated maximal severity found in this population). Validation of criteria relevance and linearity of the scales - a prerequisite for a correct evaluation process - was obtained by implementing a paired test approach ${ }^{16-18}$ that consisted of a classification by 15 volunteers in standardized conditions of lighting, position, and screen calibration of each grade for a considered scale by comparing all the possible pairs of two grades. This step allowed the establishment of grades which were significantly different from others and, therefore, to remove, adjust, or change pictures, which ensured the absence of discrimination.

The seven new standardized photographic scales and their respective correlation coefficients with real/chronological age, photoaging status, and perceived apparent age are presented in Table 3. In addition, Figures 1 and 2 present examples of new facial signs for pigmentation disorders and wrinkles and skin texture clinical clusters, which allow an accurate and reproducible evaluation to be performed according to definitions.

\section{Evaluation and scoring of skin aging signs}

This step consists in visualizing photographs by a panel of experts for grading the severity of all facial signs according to referential material described in Skin Aging Atlas, Volume 2, Asian Type ${ }^{14}$ (as presented in Table 4) and the seven new developed atlases (Table 3). By merging the two sets of clinical scales (book and new atlases) a complete and global mapping of 28 facial signs can be recorded covering four major clinical domains: wrinkles and skin texture, ptosis and sagging, pigmentation disorders, and other skin alterations such as cheek sebaceous pores and vascular disorders.

A panel of 14 experts assessed these 28 signs in all photographs that had been resized and reframed under standard operational procedures with editing software (Photoshop version $10^{\circledR}$ ). This step ensured that a given sign was only displayed on the screen. All pictures were presented to each expert at random to eliminate bias. To ensure the robustness of this process, several pictures were presented twice during the evaluation process. The latter was performed under standardized conditions of lighting, position (expert being seated 1 meter from the screen), and calibration (24-inch, $1,920 * 1,200$-pixel high-resolution screen calibrated with a colorimeter). The average score of a given facial sign was therefore calculated for each subject.

\section{Scoring of perceived apparent age}

Perceived apparent age of subjects was recorded by asking 30 naive Asian panelists (between 18 and 60 years old without any specification of marital status or occupation) to attribute a perceived apparent age to each subject by answering the following question while visualizing her full-face 
Table $3 \mathrm{New}$ clinical signs to complete previously published clinical atlases. Correlations with real/chronological age, perceived apparent age, and photoaging status

\begin{tabular}{|c|c|c|c|c|c|}
\hline $\begin{array}{l}\text { Clinical } \\
\text { cluster }\end{array}$ & Signs & $\begin{array}{l}\text { Photoaging } \\
\text { status }\end{array}$ & $\begin{array}{l}\text { Real/chronological } \\
\text { age }\end{array}$ & $\begin{array}{l}\text { Perceived } \\
\text { apparent age }\end{array}$ & Visual \\
\hline $\begin{array}{l}\text { Wrinkles and } \\
\text { skin texture }\end{array}$ & $\begin{array}{l}\text { Importance of facial skin surface } \\
\text { texture presenting alteration } \\
\text { Percentage of facial skin surface } \\
\text { presenting thick and cracked } \\
\text { aspect characteristic to solar } \\
\text { elastosis }\end{array}$ & 0.793 & 0.826 & 0.884 & \\
\hline $\begin{array}{l}\text { Wrinkles and } \\
\text { skin texture }\end{array}$ & $\begin{array}{l}\text { Texture of the mouth contour } \\
\text { Skin around the mouth has thick } \\
\text { and cracked aspect, characteristic } \\
\text { of solar elastosis }\end{array}$ & 0.729 & 0.830 & 0.889 & \\
\hline $\begin{array}{l}\text { Pigmentation } \\
\text { disorders }\end{array}$ & $\begin{array}{l}\text { Forehead pigmentation } \\
\text { Hyperpigmentation of the forehead } \\
\text { giving a "burn" aspect to the skin }\end{array}$ & 0.766 & 0.794 & 0.851 & \\
\hline $\begin{array}{l}\text { Pigmentation } \\
\text { disorders }\end{array}$ & $\begin{array}{l}\text { Cheekbone pigmentation } \\
\text { Area with pigmentation disorders } \\
\text { present on the protruding part } \\
\text { of the malar zone }\end{array}$ & 0.821 & 0.784 & 0.804 & \\
\hline $\begin{array}{l}\text { Pigmentation } \\
\text { disorders }\end{array}$ & $\begin{array}{l}\text { Lateral facial pigmentation } \\
\text { Severity of pigmentation disorders } \\
\text { on pigmentary spots on external } \\
\text { lateral area of the face }\end{array}$ & 0.750 & 0.727 & 0.769 & \\
\hline $\begin{array}{l}\text { Pigmentation } \\
\text { disorders }\end{array}$ & $\begin{array}{l}\text { Upper lip pigmentation } \\
\text { Hyperpigmentation of the upper lip } \\
\text { giving a "burn" aspect to the skin }\end{array}$ & 0.750 & 0.683 & 0.751 & \\
\hline Others & $\begin{array}{l}\text { Vascular disorders } \\
\text { All diffused redness } \\
\text { and microvessels visible on } \\
\text { the face and especially cheek }\end{array}$ & 0.574 & 0.514 & 0.507 & \\
\hline
\end{tabular}

Note: The clinical signs gathered here complete the ones previously described and published in Bazin R, Flament F. Skin Aging Atlas.Volume 2,Asian Type. Paris: Editions Med'Com; 20I0.14

photograph: "How old do you think this woman is?” All 301 perceived apparent ages were further averaged.

\section{Scoring of photoaging status}

The 301 photographs were also evaluated by three experts using the two scales developed by Chung et al. ${ }^{5}$ for recording the overall severities of facial wrinkles (8-grade scale) and facial dyspigmentation (6-grade scale). A resulting photoaging status of each subject was, therefore, obtained by adding both "wrinkles" and "pigmentation" grades.

\section{Statistics}

Analysis of variance on one factor, followed by a Tukey's comparison test, was used to investigate the link between age 


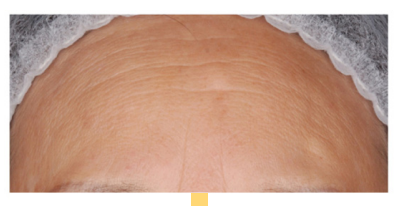

Grade 0

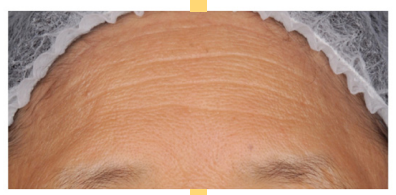

Grade 1

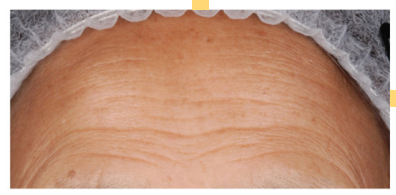

Grade 2

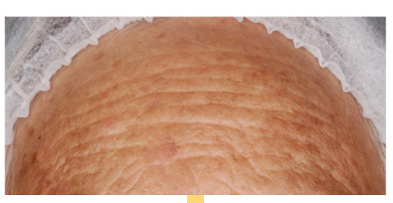

Grade 5

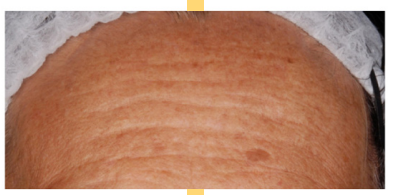

Grade 4

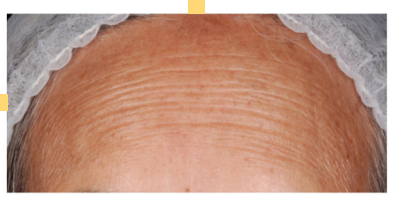

Grade 3
Figure I Clinical standardized photographic scale of "forehead pigmentation".

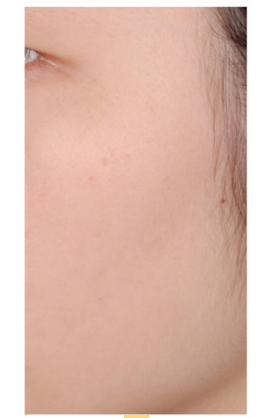

Grade 0

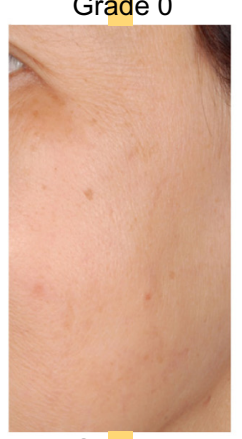

Grade 1

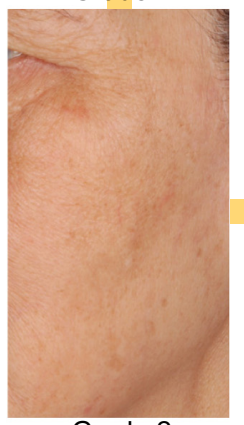

Grade 2

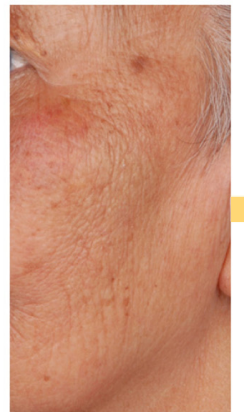

Grade 5

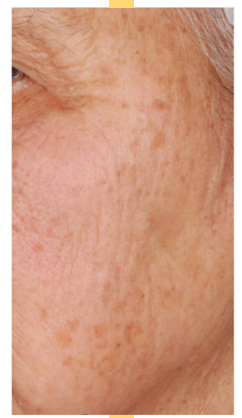

Grade 4

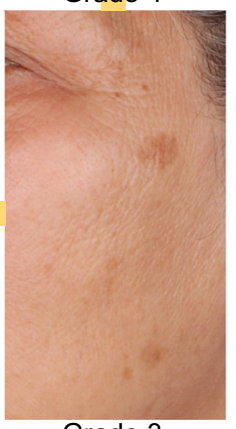

Grade 3

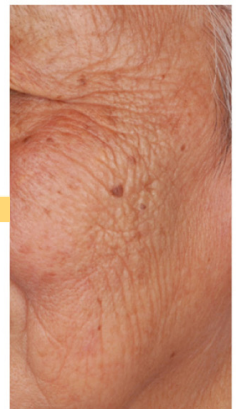

Grade 6
Figure 2 Clinical standardized photographic scale of "importance of facial skin surface texture presenting alteration". and photoaging status. The effects of age and UV exposure were characterized by a sum of clinical criteria divided into four clusters (wrinkles and skin texture, ptosis and sagging, pigmentation disorders, and other skin alterations such as cheek sebaceous pores and vascular disorders) defined in Tables 3-5. To determine the influence of UV exposure upon clinical signs in each age class, Pearson coefficients were computed between these four clinical clusters and photoaging status as well as between the clinical parameters and the real/ chronological age of each volunteer. The correlation with perceived apparent age was also calculated to ensure the most relevant clinical signs in perceived apparent age perception. To avoid any bias, all values from different grades of scales were normalized to a $0-5$ scale.

A $t$-test for independent samples was used to compare groups in each 10-year clusters for NE and S-P panels. A similar statistical approach was used to compare the difference between perceived apparent and real/chronological ages. A chi-square test was used to compare groups, with $P<0.05$ the threshold of statistical significance in all cases. Distribution normality of values for every studied population class was performed and checked with the Shapiro-Wilk test.

\section{Results}

Figure 3 illustrates for each subcohort and age class the changes in the photoaging status according to Chung's classification. ${ }^{5}$ The youngest age class excepted, where grades are the lowest (ie, more susceptible to imprecision in scoring), no significant differences were observed between S-P and NE subjects. Although photoaging status clearly increases with age class, this parameter does not allow a significant distinction between the two different behaviors with regard to sun exposure.

Figures 4-6 show the differences in wrinkles and skin texture, pigmentation, and ptosis signs between NE and S-P groups, for each 10-year cluster. The other criteria (cheek sebaceous pores and vascular disorders) are not shown here because of a lower association with age and photoaging status. These figures clearly indicate significant differences in all age classes, that is, all being aggravated by increased sun exposure and, in both cases, a rather constant increase in severity along the life span. It is noteworthy that sun-exposed subjects show a significantly faster rate of increased severity than S-P subjects.

Tables 3-5 present, for each facial clinical sign within the four clinical clusters, the various coefficients of correla- 
Table 4 Clinical aging signs of the face, described by atlases. Correlations with real/chronological age, perceived apparent age, and photoaging status

\begin{tabular}{|c|c|c|c|c|}
\hline Clinical cluster & Signs & $\begin{array}{l}\text { Photoaging } \\
\text { status }\end{array}$ & $\begin{array}{l}\text { Real/chronological } \\
\text { age }\end{array}$ & $\begin{array}{l}\text { Perceived } \\
\text { apparent age }\end{array}$ \\
\hline Wrinkles and skin texture & Forehead wrinkles & 0.740 & 0.854 & 0.894 \\
\hline Wrinkles and skin texture & Fine lines of the forehead & 0.762 & 0.868 & 0.915 \\
\hline Wrinkles and skin texture & Glabellar wrinkles & 0.617 & 0.765 & 0.788 \\
\hline Wrinkles and skin texture & Interocular wrinkles & 0.698 & 0.859 & 0.874 \\
\hline Wrinkles and skin texture & Crow's feet wrinkles & 0.773 & 0.880 & 0.901 \\
\hline Wrinkles and skin texture & Underneath eye wrinkles & 0.803 & 0.899 & 0.935 \\
\hline Wrinkles and skin texture & Preauricular wrinkles & 0.708 & 0.792 & 0.828 \\
\hline Wrinkles and skin texture & Cheek folds & 0.788 & 0.848 & 0.896 \\
\hline Wrinkles and skin texture & Nasolabial fold & 0.706 & 0.851 & 0.898 \\
\hline Wrinkles and skin texture & Small folds on nasolabial zone & 0.763 & 0.907 & 0.938 \\
\hline Wrinkles and skin texture & Upper lip wrinkles & 0.735 & 0.837 & 0.890 \\
\hline Wrinkles and skin texture & Wrinkles of the corner of the lips & 0.682 & 0.823 & 0.857 \\
\hline Wrinkles and skin texture & Chin withering & 0.634 & 0.731 & 0.771 \\
\hline Pigmentation disorders & Density of pigmentary spots & 0.803 & 0.703 & 0.730 \\
\hline Pigmentation disorders & Localized pigmentary spots of the cheek & 0.774 & 0.694 & 0.742 \\
\hline Pigmentation disorders & Contrast of isolated pigmentary spot of the face & 0.635 & 0.587 & 0.617 \\
\hline Pigmentation disorders & Size of an isolated spot & 0.623 & 0.577 & 0.613 \\
\hline Ptosis and sagging & Drooping of upper outer eyelid & 0.712 & 0.839 & 0.869 \\
\hline Ptosis and sagging & Eye bags & 0.739 & 0.865 & 0.885 \\
\hline Ptosis and sagging & Ptosis of the lower part of the face & 0.689 & 0.814 & 0.848 \\
\hline Others & Cheek sebaceous pores & 0.103 & 0.143 & 0.126 \\
\hline
\end{tabular}

Note: Standardized photographic scales used for scoring were previously published in Bazin R, Flament F. Skin Aging Atlas. Volume 2, Asian Type. Paris: Editions Med'Com; 2010.14

Table 5 The four clinical clusters. Correlations with real/ chronological age, perceived apparent age and photoaging status

\begin{tabular}{|c|c|c|c|}
\hline $\begin{array}{l}\text { Clinical } \\
\text { cluster }\end{array}$ & $\begin{array}{l}\text { Photoaging } \\
\text { status }\end{array}$ & $\begin{array}{l}\text { Real/chronological } \\
\text { age }\end{array}$ & $\begin{array}{l}\text { Perceived } \\
\text { apparent age }\end{array}$ \\
\hline $\begin{array}{l}\text { Wrinkles and } \\
\text { skin texture } \\
\text { (15 signs) }\end{array}$ & 0.803 & 0.925 & 0.967 \\
\hline $\begin{array}{l}\text { Pigmentation } \\
\text { disorders } \\
\text { (8 signs) }\end{array}$ & 0.829 & 0.778 & 0.823 \\
\hline $\begin{array}{l}\text { Ptosis and } \\
\text { sagging ( } 3 \text { signs) }\end{array}$ & 0.775 & 0.913 & 0.943 \\
\hline Others (2 signs) & 0.414 & 0.412 & 0.398 \\
\hline
\end{tabular}

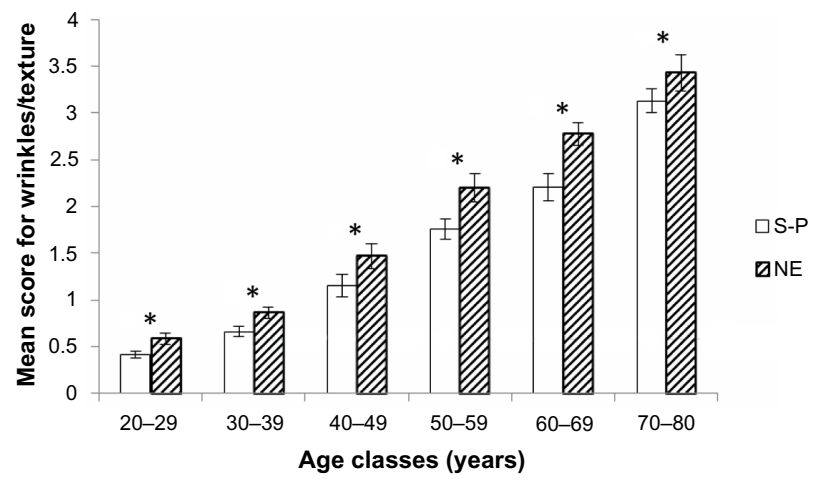

Figure 4 Comparison of wrinkles and skin texture. Mean scores $( \pm 95 \% \mathrm{Cl})$ for each age class between normal exposure and sun-phobic. Note: *Statistically significant difference $(P<0.05)$.

Abbreviations: S-P, sun-phobic; $\mathrm{NE}$, normal exposure; $\mathrm{Cl}$, confidence interval.

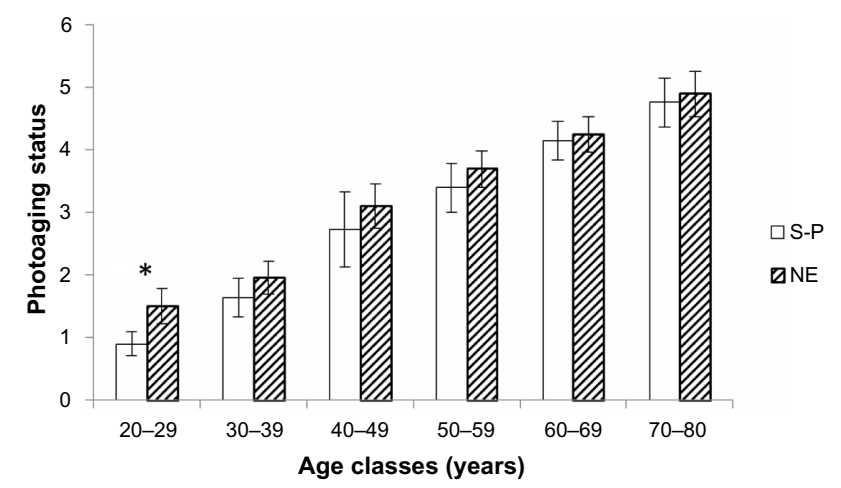

Figure 3 Comparison of photoaging status scored with Chung's scales. ${ }^{5}$ Mean scores $( \pm 95 \% \mathrm{Cl})$ for each age class between normal exposure and sun-phobic. Note: *Statistically significant difference $(P<0.05)$.

Abbreviations: S-P, sun-phobic; $\mathrm{NE}$, normal exposure; $\mathrm{Cl}$, confidence interval.

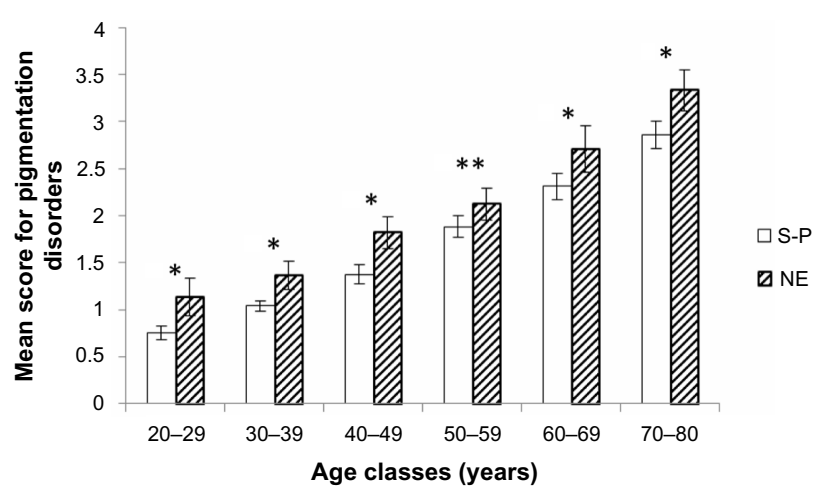

Figure 5 Comparison of pigmentation disorders. Mean scores $( \pm 95 \% \mathrm{Cl})$ for each age class between normal exposure and sun-phobic.

Notes: *Statistically significant difference $(P<0.05)$; **tendency $(P<0 . I)$.

Abbreviations: S-P, sun-phobic; NE, normal exposure; $\mathrm{Cl}$, confidence interval. 


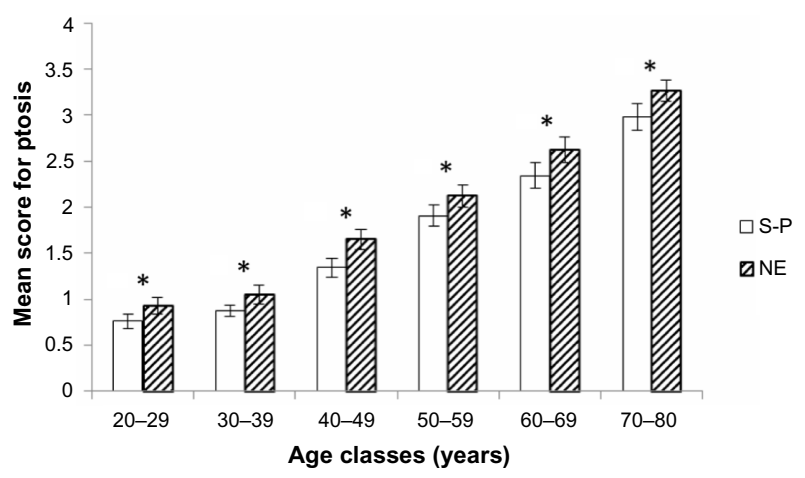

Figure 6 Comparison of ptosis and sagging. Mean scores $( \pm 95 \% \mathrm{Cl})$ for each age class between normal exposure and sun-phobic.

Note: *Statistically significant difference $(P<0.05)$.

Abbreviations: S-P, sun-phobic; NE, normal exposure; $\mathrm{Cl}$, confidence interval.

tion between severity and age (perceived apparent and real/ chronological) and photoaging status. Table 5 clearly shows strong relationships of wrinkles, pigmentation, and ptosis criteria with both age and photoaging status, whereas skin pores and vascular disorders are of much lower incidence. It is noteworthy that the severity of all facial signs of wrinkles, ptosis, and pigmentation appear systematically better correlated (higher values) with perceived apparent age than real/ chronological age.

To go further in approaching sun exposure impact and discrimination of intrinsic and extrinsic causes in aging, a comparison was carried out of the first quartile of the S-P group, that is, women presenting less sun-induced damage in the population with strong protective habits against solar exposure and appearance closer to chronological aging, and the fourth quartile of the NE group, that is, women presenting maximum sun-induced damage in people who do not take specific precautions against radiation and so appear more photoaged. By subtracting the two values in each age class, an amplification factor of sun assault was identified. Up to 70 years old, except for ptosis/sagging, aging signs could have been twice as high without protective behavior to solar exposure. These illustrative data could be observed in Table 6, and a lower impact of sun on ptosis/sagging criteria than on three other clinical clusters could be noticed.

The effects of solar exposure on our appearance, that is, perceived apparent age, are summarized in Table 7 and Figure 7. Table 7 illustrates how S-P subjects are perceived as slightly younger (by a 3 year difference) than NE subjects. However, such differences vary according to real/chronological age, as shown by Figure 7. The latter are expressed as absolute values (perceived apparent age minus real/chronological age), that is, positive values imply a perceived apparent age older than real/chronological age. Figure 7 clearly shows that, the youngest age class excepted, all S-P Asian women are judged younger than NE Asian women. Interpreting the observations from the youngest age class is difficult since, as said above, low grades likely induce increased imprecision in attributing a perceived apparent age. In fact, both groups of younger women show the largest absolute differences (up to 6 years) between perceived apparent and real/chronological ages. In brief, attributing a perceived apparent age of 26 years to a 22 year old young woman is probably high imprecision, with little meaning or consequence. Cultural specificities have to be raised at this point regarding previous internal works in Japanese populations identifying a perceived apparent age in the 20-30 year age class was already demonstrated as complex for Asian quorum and often found older than real/ chronological age.

On one hand, correlations were computed for photoaging status and, first real/chronological age (0.783), then perceived apparent age (0.813). On the other hand, a 0.969 coefficient of correlation between perceived apparent age and real/ chronological age was found. Likewise, the photoaging status is better correlated with perceived apparent age than $\mathrm{real} /$ chronological age.

\section{Discussion}

Few studies provide objective quantification of the effects of sun exposure upon the aging of the Asian or Chinese

Table 6 Estimation of maximum clinical sun-induced damages vs real/chronological Asian facial skin aging for each age class in absence of specific prevention behavior: (Mean of fourth NE quartile - mean of first S-P quartile)/mean of first S-P quartile, that is, ([extrinsic + intrinsic] - intrinsic)/intrinsic

\begin{tabular}{|c|c|c|c|c|c|}
\hline $\begin{array}{l}\text { Age } \\
\text { (years) }\end{array}$ & $\begin{array}{l}\text { Wrinkles and } \\
\text { skin texture }\end{array}$ & $\begin{array}{l}\text { Ptosis and } \\
\text { sagging }\end{array}$ & $\begin{array}{l}\text { Pigmentation } \\
\text { disorders }\end{array}$ & $\begin{array}{l}\text { Cheek sebaceous } \\
\text { pores }\end{array}$ & $\begin{array}{l}\text { Vascular } \\
\text { disorders }\end{array}$ \\
\hline $20-29$ & 3.13 & 1.97 & 4.32 & 4.19 & 21.20 \\
\hline $30-39$ & 1.23 & 1.43 & 2.43 & 2.29 & 4.86 \\
\hline $40-49$ & I.55 & 1.25 & 2.08 & 2.53 & 3.49 \\
\hline 50-59 & 1.43 & 0.87 & 1.20 & 2.47 & 1.81 \\
\hline $60-69$ & 1.13 & 0.57 & I.14 & 1.45 & 1.88 \\
\hline $70-80$ & 0.47 & 0.46 & 0.78 & I.30 & 1.62 \\
\hline
\end{tabular}

Abbreviations: S-P, sun-phobic; NE, normal exposure. 
Table 7 Differences in perceived apparent age (younger/older than 3 years) between the two subcohorts of Chinese women (sun-phobic vs normal sun exposure)

\begin{tabular}{lll}
\hline & Sun-phobic & Normal exposure \\
\hline Looks older by 3 years & $18.71 \%$ & $37.65 \%$ \\
Looks one's age & $56.83 \%$ & $46.91 \%$ \\
Looks younger by 3 years & $24.46 \%$ & $15.43 \%$ \\
\hline
\end{tabular}

face. ${ }^{4-6}$ To quantify photoaging, a very interesting clinical scale developed by Chung et al. ${ }^{5}$ allowed us to give an overall level of photoaging but did not permit the different signs to be precisely described according to the behavior of women vis à vis sun exposure. The present work aimed at providing some new features for quantifying the effects of sun exposure on Asian skin, besides those described in Skin Aging Atlas, Volume 2, Asian Type. ${ }^{14}$

The ancestral habits of most Asian women to protect their skin against the damaging effect of sun were indeed an obstacle in building two distinct groups. Accordingly, a passive/active behavior parameter to separate two groups was used to emphasize the impact of sun exposure upon the facial skin. Such clear-cut differences in behavior are more easily defined among Caucasians, where sun-seekers are much more frequent, making it difficult to objectively compare the photoaging clinical facets between Caucasian and Asian people.

In the present study, 28 different signs were used to quantify aging, clustered into four clinical domains: wrinkles and skin texture, ptosis and sagging (tissues slackening), pigmentation disorders, and others.

On one hand, quantification of the clinical signs was objectively ensured by the panel of trained experts since the experts could score only one sign from the screen without any influence from any other facial sign, conferring a better reli-

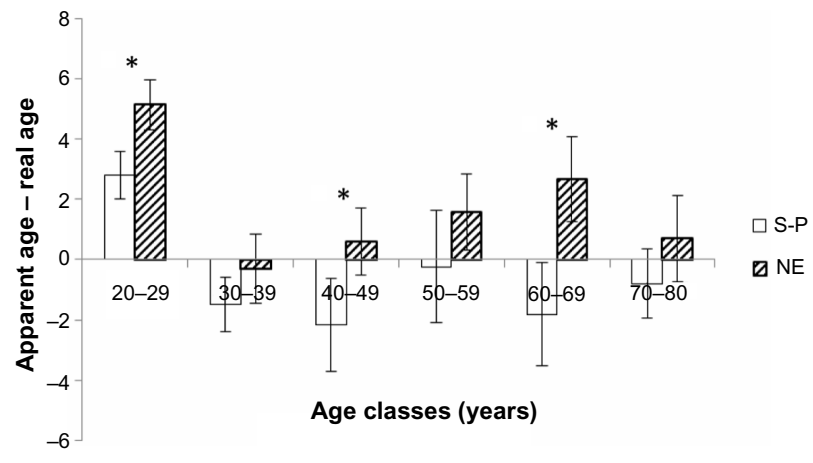

Figure 7 Difference between perceived apparent and real/chronological ages for each age class between normal exposure and sun-phobic. Mean differences $( \pm 95 \% \mathrm{Cl})$. Note: *Statistically significant difference $(P<0.05)$.

Abbreviations: S-P, sun-phobic; NE, normal exposure; $\mathrm{Cl}$, confidence interval. ability in grading. The use of photographic scales enabled us to characterize and detect even small variations, for example, when they first appear (Figures 4-6). On the other hand, unlike our previous findings obtained in French women ${ }^{8}$ where approximately $20 \%$ of facial signs appeared only chronologically related (intrinsic aging), all facial signs recorded in the studied Chinese women were, to various extents, sun-related, with, however, lower amplitudes (absolute differences in scorings). The severity of almost all Chinese facial clinical signs increased with age and more rapidly under sun exposure. Among these, signs of wrinkles and skin texture intensified rather linearly by approximately $10 \%$ per decade from age 20 to 80 years, these parameters appearing better correlated with both ages than with photoaging status. The correlation with real/chronological age (Table 5), regarding all forms of wrinkles, confirms the results of Tsukahara ${ }^{19}$ using a photographic homemade scale. In each age class, significant differences between the NE group and the S-P group were clearly observed. Sun exposure clearly aggravates the severity of these signs in sun-exposed women, since we found that severity increased by some $28 \%$ in younger women and $8 \%$ in the older group, as compared with less exposed women. By comparing S-P and NE subcohorts for each 10-year age class, significant differences have been noticed for all wrinkles/skin texture signs from age 50 years for Caucasian women and age 20 years for Asian panelists.

The clinical signs of pigmentation appeared logically driven by solar exposure, keeping in mind that, despite higher phototypes and cultural defiance toward sun exposure, UV radiation is, by far, much higher in southerner latitudes such as Guangzhou. ${ }^{20}$ From the early age classes through the complete life span, an important difference in the facial pigmentation status between NE and S-P subjects was observed, where grades above 1 were found among the younger NE group, suggesting an early onset of pigmentation disorders. With regard to wrinkles and pigmentation signs, the present results not only confirm previous data, ${ }^{6,21,22}$ but again highlight the necessity of strict sun-prevention behavior, especially during youth for Asian populations: according to Table 2, a link between sun exposure(s) during childhood/ adolescence and premature aging process has been observed for Guangzhou panelists.

As for sagging criteria, as opposed to French observations (same parameters as those used in the present study), where we failed to show a clear impact from sun, this study revealed the sun's impact upon female Chinese facial skin. The various parameters of ptosis appear more correlated with age than with photoaging status, all being significantly aggravated 
by sun exposure in all age classes. It is noteworthy that the amplitude of the sagging degradation remains below 1 grade in the two youngest classes, a value considered as a detection and quantification threshold, making significant slackening of the tissue rarely recorded before the 40-49 year age class. Although this point has not been previously described, we believe that this tissue deterioration, partly due to sun exposure, both UV and IR radiation, results from progressive alterations of the dermal extracellular matrix (collagen and elastin networks). This clinical observation was made possible by our clustering method, which was discriminating enough to separate both groups, that is, a classification more difficult to establish in Caucasians, as mentioned above.

Facial redness scores appear much better correlated with real/chronological and perceived apparent ages than skin pores, both being much less correlated with age (mostly skin pores) than all other signs. As an example, facial redness, as explored with the atlas of "vascular disorders", are correlated with real/chronological and perceived apparent ages $(0.507$ or 0.514 ) and photoaging status (0.574) but to lesser degrees than with wrinkles or pigmentation signs. The statistical difference between the S-P and NE groups for the 20-29 year and the 40-49 year age clusters - the same behavior with age (significant differences) for vascular and cheek sebaceous pores - could confirm the importance of this sign as a precursor of sun-induced damages. Table 6 also shows new objective key findings in favor of this hypothesis. According to Chung et al, ${ }^{22}$ photoaging induces "a gradual decrease in the number and size of dermal vessels over several decades of sun exposure". The global clinical atlases we used here do not afford a description with such a level of precision, but seem not to confirm these results, a point which likely needs the concourse of histological references.

For the three main clinical clusters, different behaviors with the aging process have been noticed among people of different ethnic origins (Asian vs Caucasian women) especially earlier apparition of sun-induced damage from the twenties for any clinical clusters for Asian skin. Major impacts have been noticed on signs of pigmentation disorders from the first studied age class for both populations.

The fact that almost all clinical facial signs appear better correlated with perceived apparent age than real/ chronological age is, we believe, a very important finding. This finding was also observed in our study on Caucasian women. ${ }^{8}$ It confirms previous work ${ }^{23-25}$ where perceived apparent age was used as a biomarker since people perceived younger were indeed younger, biologically. This fully justi- fies the famous aphorism that "the book is judged by its cover". In brief, we are what we look like.

Apart from dermatological (or cosmetic) applications, the findings suggest that perceived apparent age might be a better indicator of the "true" biological age of a given individual in other medical disciplines. Would such parameters better correlate with physiological constants recorded in cardiology, hematology, or enterology? This possibility deserves, we believe, high attention. If applied with success to one of these medical branches, it would then fully justify the quote from the French philosopher Paul Valery (1931, "L'idée fixe"), "what is most deep is the skin".

\section{Conclusion}

As compared with their Caucasian counterparts, where sun-induced damage represents approximately $80 \%$ of aging signs in sun-seeking subjects, all facial signs of Asian women studied seem to present a sun-related origin, in addition to the chronological aging process. These are not only of a lesser degree of severity among S-P Asian women, but of slightly lower amplitudes than those seen in Caucasian women. Despite an old cultural "beware of sun" warning and higher skin phototypes, a much more intense UV radiation is found in southern People's Republic of China and an early onset of cutaneous alterations. Use of complete clinical scale references for precise quantification of the degree of photoaging is a pathway for fast and accurate diagnosis and definition of specific treatments (for prevention/correction). In almost all cases, chronological and/or sun-induced changes in facial signs do impact age perception to the extent that they appear better correlated with perceived apparent age than real/ chronological age.

\section{Acknowledgments}

The authors wish to thank Mr Didier Saint-Leger, Mrs Xiaohui Long, Mr Jerome Senee, Mr Stephane Ortiz, Mrs Celine Cornillon, Mr Dominique Batisse, Mr Thierry Cotton, Mr David Amar and Mr Stephane Diridollou, not only for their great help in completion of this paper and global study, but also for their strong support and enthusiasm.

\section{Disclosure}

The authors report no conflicts of interest in this work.

\section{References}

1. Gilchrest BA. Skin aging and photo aging: an overview. J Am Acad Dermatol. 1989;21:610-613. 
2. Zhao P, Zhu X, Liu Y, Wang B, Wang C, Burns FJ. Solar ultraviolet radiation and skin damage: an epidemiological study among a Chinese population. Arch Environ Health. 1998;53:405-409.

3. Eun HC. Cutaneous photodamage in Asians. J Dermatol. 2001;28: 614-616.

4. Chung JH. Photoaging in Asians. Photodermatol Photoimmunol Photomed. 2003;19:109-121.

5. Chung JH, Lee SH, Youn CS, et al. Cutaneous photodamage in Koreans: influence of sex, sun exposure, smoking, and skin color. Arch Dermatol. 2001;137:1043-1051.

6. Akiba S, Shinkura R, Miyamoto K, Hillebrand G, Yamaguchi N, Ichihashi M. Influence of chronic UV exposure and lifestyle on facial skin photo-aging - results from a pilot study. J Epidemiol. 1999; 9(Suppl 6):S136-S142.

7. Nouveau-Richard S, Yang Z, Mac-Mary S, et al. Skin ageing: a comparison between Chinese and European populations: A pilot study. J Dermatol Sci. 2005;40:187-193.

8. Flament F, Bazin R, Laquieze S, Rubert V, Simonpietri E, Piot B. Effect of the sun on visible clinical signs of aging in Caucasian skin. Clin Cosmet Investig Dermatol. 2013;6:221-232.

9. Sabziparvar AA, Shine KP, Forster PM. A model-derived global climatology of UV irradiation at the Earth's surface. Photochem Photobiol. 1999;69(2):193-202.

10. Wu Y, Gao K, Li G, Helbing EW. Seasonal impacts of solar UV radiation on photosynthesis of phytoplankton assemblages in the coastal waters of the South China Sea. Photochem Photobiol. 2010;86:586-592.

11. Holzer AM, Elmets CA. The other end of the rainbow: Infrared and skin. J Invest Dermatol. 2010;130(6):1496-1499.

12. Schroeder P, Lademann J, Darvin ME, et al. Infrared radiation-induced matrix metalloproteinase in human skin: implications for protection. J Invest Dermatol. 2008;128:2491-2497.

13. Kennedy C, Bastiaens MT, Bajdik CD, Willemze R, Westendorp RGJ, Bouwes Bavinck JN; Leiden Skin Cancer Study. Effect of smoking and sun on the aging skin. J Invest Dermatol. 2003;120:548-554.
14. Bazin R, Flament F. Skin Aging Atlas. Volume 2, Asian Type. Paris: Editions Med'Com; 2010.

15. Kim EJ, Han JY, Lee HK, et al. Effect of the regional environment on the skin properties and the early wrinkles in young Chinese women. Skin Res Technol. 2014;20(4):498-502.

16. Bazin R, Flament F, Giron F. Skin Aging Atlas. Volume 3. Afro-American Type. Paris: Editions Med'Com; 2012.

17. David HA. The Method of Paired Comparisons. 2nd ed. London: Charles Griffin and Company, 1988.

18. Gacula MC, Singh J. Statistical Methods in Food Consumer Research. Orlando, FL: Academic Press; 1984:410-424.

19. Tsukahara K, Sugata K, Ohushi A, et al. Comparison of age-related changes in facial wrinkles and sagging in the skin of Japanese, Chinese and Thai women. J Dermatol Sci. 2007;47:19-28.

20. Jablonski NG, Chaplin G. Colloquium paper: human skin pigmentation as an adaptation to UV radiation. Proc Natl Acad Sci U S A. 2010;107(Suppl 2):8962-8968.

21. Goh SH. The treatment of visible signs of senescence: the Asian experience. Br J Dermatol 1990;122(Suppl 35):105-109.

22. Chung JH. The effects of sunlight on the skin of Asians. In: Giacomoni PU, editor. Sun Protection in Man. Amsterdam: Elsevier Science BV. 2001; 69-90.

23. Mayes AE, Murray PG, Gunn DA, et al. Environmental and lifetime factors associated with perceived facial age in Chinese women. PLoS One. 2010;5(12):e15270.

24. Christensen K, Thinggaard M, Mc Gue M, et al. Perceived age as a clinically useful bio-marker of ageing: cohort study. BMJ. 2009;339: b5262.

25. Kligman AM. Psychological aspects of skin disorders in the elderly. Cutis. 1989;43:498-501.
Clinical, Cosmetic and Investigational Dermatology

\section{Publish your work in this journal}

Clinical, Cosmetic and Investigational Dermatology is an international, peer-reviewed, open access, online journal that focuses on the latest clinical and experimental research in all aspects of skin disease and cosmetic interventions. All areas of dermatology will be covered; contributions will be welcomed from all clinicians and

\section{Dovepress}

basic science researchers globally. This journal is indexed on CAS The manuscript management system is completely online and includes a very quick and fair peer-review system, which is all easy to use. Visit http://www.dovepress.com/testimonials.php to read real quotes from published authors. 